\title{
Sexual isolation studies of Drosophila kanekoi
}

\author{
By Hide-aki WATABE* and Chizuko HIGUCHI** \\ * Biological Laboratory, Sapporo College, Hokkaido University of Education, \\ Sapporo 064 \\ ** Zoological Institute, Faculty of Science, Hokkaido University, \\ Sapporo 060
}

(Received May 1, 1983)

\begin{abstract}
Interspecific crossability between Drosophila kanekoi and other members of the $D$. virilis group was studied by using no choice and female choice methods. Asymmetric mating preference was observed in every cross. Females of $D$. kanekoi more frequently mated to males of $D$. virilis, $D$. lummei and of $D$. montana montana than in the reciprocal crosses. A complete sexual isolation was found between two sympatric species, $D$. kanekoi and $D$. ezoana.
\end{abstract}

\section{INTRODUCTION}

The virilis species group consists of eleven species, some of which include subspecies. They are distributed in both Palaearctic and Nearctic regions, except for a domestic, world-wide species of $D$. virilis. Evolution of this group has extensively been studied by means of sexual isolation (Stalker 1942b), interspecific chromosome analysis, morphological and biochemical comparisons (Stone et al. 1960; Throckmorton 1982). Drosophila kanekoi has recently been described from Hokkaido, Japan (Watabe and Higuchi 1979). It is of ten observed in Hokkaido that D. kanekoi and D. ezoana are sympatrically distributed particularly in riparian zone. This paper presents the crossability between $D$. kanekoi and the other members of this species group.

\section{MATERIALS AND METHODS}

Seven iso-female lines were used. These were as follows; $D$. virilis (Sapporo, Japan), D. lummei (Oulu, Finland), D. littoralis (Strängnäs, Sweden), D. ezoana (Sapporo, Japan), D. montana montana (Cottonwood Canyon, Utah, U.S. A.), D. montana ovivororum (Kiuruvesi, Finland) and D. kanekoi (Chitose, Japan).

No Choice Method: Newly emerged flies were etherized every day and sorted for sex, and were stored in vials (40 $\mathrm{mm}$ in diameter, $120 \mathrm{~mm}$ in height) with usual yeast medium at room temperature $\left(18-30^{\circ} \mathrm{C}\right)$ for one to two days. 
Table 1. Frequencies (\%) of inseminated females in no choice method and production of hybrids between the members of the Drosophila virilis group. $F$ : hybrids produced $\left(F_{1}\right)$,

$N$ : no hybrid produced

\begin{tabular}{|c|c|c|c|c|c|c|c|}
\hline \multirow{2}{*}{ female } & \multicolumn{7}{|c|}{ male } \\
\hline & Vi & $\mathrm{Lu}$ & Lt & $\mathrm{Ez}$ & Mo & $\mathrm{Ov}$ & $\mathrm{Ka}$ \\
\hline D. virilis (Vi) & - & $\underset{F}{58.6}(31)$ & $\underset{\mathrm{F}}{90.3}(31)$ & $\dot{\mathbf{N}}^{\mathbf{N}} \mathbf{( 3 3 )}$ & $\underset{\mathrm{F}}{47.3(39)}$ & $\underset{F}{34.8}(23)$ & $26.2(80)$ \\
\hline D. lummei (Lu) & $\underset{F}{88.8}(27)$ & - & $\underset{F}{62.5}(32)$ & $\underset{N}{0.0}(26)$ & $\underset{F}{72.7(55)}$ & $32.2(31)$ & $17.0(47)$ \\
\hline D. littoralis (Lt) & $\ddot{N}^{82.7}(29)$ & $11.7(34)$ & - & $20.0(55)$ & $\underset{F}{40.0(40)}$ & & $12.0(75)$ \\
\hline D. ezoana (Ez) & $4.1 \mathrm{~N}(24)$ & $\underset{\mathrm{N}}{0.0(22)}$ & ${ }_{\mathrm{N}}^{35.5(34)}$ & - & ${ }_{\mathrm{N}}^{51.0}(35)$ & $35.8(39)$ & $\dot{\mathrm{N}}^{0.0(27)}$ \\
\hline D. montana & $\underset{\mathrm{F}}{50.0}(38)$ & $\stackrel{33.3}{\mathbf{N}}(27)$ & $\underset{F}{3.2(39)}$ & $20.5(34)$ & - & & $\dot{\mathrm{N}}^{0.0(35)}$ \\
\hline $\begin{array}{l}\text { D. montana } \\
\text { ovivororum (Ov) }\end{array}$ & $\underset{\mathrm{N}}{8.0}(23)$ & $\stackrel{23.3}{\mathrm{~N}}(30)$ & & $\underset{\mathrm{N}}{0.0(29)}$ & & - & $\underset{\mathrm{N}}{0.0(20)}$ \\
\hline D. kanekoi (Ka) & $84.5(58)$ & $42.8(56)$ & ${ }_{\mathrm{N}}^{77.7}(18)$ & ${ }_{N}^{1.1(26)}$ & $\underset{F}{86.6(60)}$ & $\dot{\mathrm{N}}_{\mathrm{N}}(\mathbf{3 1})$ & 一 \\
\hline
\end{tabular}

The numbers in parentheses give the number of females examined.

Then, five males and the same number of alien females were placed together in a vial $(30 \mathrm{~mm}$ in diameter, $120 \mathrm{~mm}$ in height) and reared for 30 days at $18^{\circ} \mathrm{C}$ under continuous light. Thereafter, females were dissected and examined for sperm in both spermathecae and seminal receptacles. Six to twelve replicates were made for each cross. In addition, the culture vials were also examined for presence of larvae.

Female Choice Method: Five males were placed together with ten females, five of conspecific females and five of alien ones, in a vial. They were reared for one day at $18^{\circ} \mathrm{C}$ under continuous illumination. There were clear differences from species to species in the period of sexual maturation; $D$. virilis and D. lummei females began to mate before the maturation of the ovaries, while $D$. kanekoi and D. m. montana females did not mate before their ovaries were fully developed. Therefore, 24-days old flies were used for every cross. The degree of sexual isolation was indicated by the isolation index (I.I.) (Stalker 1942b).

\section{RESULTS AND DISCUSSION}

Table 1 shows the results of the crossability by using no choice method. The females of $D$. kanekoi mated well to the males of $D$. virilis, D. lummei, $D$. littoralis and of D. m. montana, but scarcely to those of $D$. ezoana and $D$. $m$. ovivororum. On the other hand, the males of $D$. kanekoi hardly mated to 
Table 2. Sexual isolation between Drosophila kanekoi (Ka) and three species, D. virilis (Vi), D. lummei (Lu) and D. montana montana (Mo) of the virilis group

\begin{tabular}{|c|c|c|c|c|c|c|c|c|c|}
\hline \multicolumn{2}{|c|}{$\begin{array}{l}\text { Cross } \\
\text { Female }\end{array}$} & \multirow{2}{*}{$\begin{array}{l}\text { Male } \\
\mathrm{Ka}\end{array}$} & \multicolumn{2}{|c|}{$\begin{array}{l}\text { Homogamic } \\
(+) \quad(-)\end{array}$} & \multicolumn{2}{|c|}{$\underset{(+)}{\text { Heterogamic }}(-)$} & \multirow{2}{*}{$\frac{\begin{array}{c}\% \text { of Homo- } \\
\text { gamic }(+)\end{array}}{100}$} & \multirow{2}{*}{$\begin{array}{c}\text { \% of Hetero- } \\
\text { gamic }(+) \\
0\end{array}$} & \multirow{2}{*}{$\begin{array}{l}\text { I. I. } \\
1.00\end{array}$} \\
\hline $\mathrm{Ka}$ & $\mathrm{Vi}$ & & 60 & 0 & 0 & 60 & & & \\
\hline $\mathrm{Ka}$ & $\mathrm{Vi}$ & $\mathrm{Vi}$ & 47 & 4 & 5 & 54 & 92.1 & 10.2 & 0.80 \\
\hline $\mathbf{K a}$ & $\mathrm{Lu}$ & $\mathrm{Ka}$ & 24 & 1 & 8 & 23 & 96 & 34.7 & 0.46 \\
\hline $\mathrm{Ka}$ & $\mathrm{Lu}$ & $\mathrm{Lu}$ & 20 & 11 & 2 & 33 & 64.5 & 5.7 & 0.83 \\
\hline $\mathrm{Ka}$ & Mo & $\mathrm{Ka}$ & 35 & 0 & 0 & 38 & 100 & 0 & 1.00 \\
\hline $\mathrm{Ka}$ & Mo & Mo & 55 & 0 & 23 & 31 & 100 & 42.6 & 0.40 \\
\hline
\end{tabular}

Homogamic $(+)$ and Heterogamic $(+)$ indicate the number of females inseminated by their own males and by alien males, respectively.

alien females. Both males and females of $D$. virilis well mated to the other species, except for $D$. ezoana. During the cross experiment of $D$. kanekoi females with $D$, ezoana males, 3 kanekoi females died by 30 th days after their exposure but they had all been inseminated. Since none of alive female had been inseminated in this case, the interspecific insemination seemed to have a lethal role for $D$. kanekoi females. Although $D$. kanekoi and D. ezoana are often found to live together particularly in riparian zone, the data represented in this study imply that there is a strong, reproductive isolating mechanism between the species and their gene pools are thus discrete mutually.

Table 2 gives the results of the interspecific sexual isolation by using female choice method. The I. I. values are low between $D$. lummei females and $D$. kanekoi males and between $D$. kanekoi females and D. m. montana males. This result is coincident with that obtained in the experiment using no choice method, except for the cross between $D$. lummei females and $D$. kanekoi males.

The virilis species group consists of two major lineages, the virilis and the montana phylads (Throckmorton 1982). Watabe and Higuchi (1979) have reported that $D$. kanekoi has morphologically combined characteristics of the both phylads. In this connection, Throckmorton (personal communication) suggests that $D$. kanekoi has "dot chromosome", a characteristic of the montana phylad, while it has a "small ejaculatory bulb", a characteristic of the virilis phylad. These facts may reflect the mating preference revealed here that the females of $D$. kanekoi well accepted the males of either of the phylad. Further, by means of protein analysis, Throckmorton (1982) states that this species can be considered to be derived at early stage of the speciation of the virilis group. The facts mentioned above lead to conclusion that $D$. kanekoi might be an oldest member which occupies phylogenetically 
important position between the two phylads of this group.

We wish to express our sincere thanks to Prof. L. H. Throckmorton, University of Chicago, to Prof. S. Lakovaara, University of Oulu, and to Dr. A. Kaneko, Japanese Ministry of Education, Science and Culture, for their invaluable advices and for sending us the precious materials. We are also grateful to Dr. E. Momma and Dr. M. T. Kimura for their helpful advices.

\section{REFERENCES}

STALKER, H. D. (1942) Sexual isolation studies in the species complex Drosophila virilis. Genetics 27, 238-257.

Stone, W. S., Guest, W. C. and WiLson, F. D. (1960) The evolutionary implication of the cytological polymorphism and phylogeny of the virilis group of Drosophila. Proc. Natl. Acad. Sei. U. S. A. 46, 350-361.

Throckmorton, L. H. (1982) The virilis group. The Genetics and Biology of Drosophila (ed. Ashburner, M., Carson, H. L. and Thompson Jr., J. N.), 3b, pp. 227-296. Academic Press, New York.

Watabe, H. and Higuchi, C. (1979) On a new species of the virilis group of the genus Drosophila (Diptera, Drosophilidae), with revision of the geographical distribution of the group. Annot. Zool. Japon. 52, 203-211. 